\title{
The association between self-reported lack of sleep, low vitality and impaired glucose tolerance: a Swedish cross-sectional study
}

\author{
Susanne Andersson ${ }^{1,2}$, Inger Ekman ${ }^{1,3}$, Febe Friberg ${ }^{1,4}$, Erik Bøg-Hansen ${ }^{5}$ and Ulf Lindblad ${ }^{5,6^{*}}$
}

\begin{abstract}
Background: The increased incidence of impaired glucose tolerance (IGT), are serious public health issues, and several studies link sleeping disorders with increased risk of developing type 2 diabetes, impaired glucose tolerance and insulin resistance (IR). This study explore how self-reported lack of sleep and low vitality, are associated with IGT in a representative Swedish population.

Methods: A cross-sectional survey conducted in two municipalities in South-western Sweden. Participants aged 30-75 were randomly selected from the population in strata by sex and age. Altogether, 2,816 participants were surveyed with a participation rates at $76 \%$. Participants with normal glucose tolerance $(n=2,314)$, and those with IGT $(n=213)$ were retained for analyses. The participants answered a questionnaire before the oral glucose tolerance test (OGTT). Associations for questions concerning sleeping disorders, vitality and IGT were analysed using logistic regression and were expressed as odds ratios (OR) with 95\% Cl.
\end{abstract}

Results: In men a statistically significant age-adjusted association was found between self-reported lack of sleep and IGT: OR 2.4 (95\% Cl: 1.1-5.4). It did not weaken after further adjustment for body mass index (BMI), smoking, education, and leisure time physical activity 2.3 (1.0-5.5, $\mathrm{p}=0.044)$. No such associations were found in females. Corresponding age-adjusted associations between low vitality and IGT in both men 2.8 (1.3-5.8), and women 2.0 (1.2-3.4) were successively lost with increasing adjustment.

Conclusions: Insufficient sleep seems independently associated with IGT in men, while low vitality was not independently associated with IGT neither in men nor women, when multiple confounders are considered. IGT should be considered in patients presenting these symptoms, and underlying mechanisms further explored.

Keywords: Impaired glucose tolerance, Fatigue, Sleeping disorders, Health conversation, Primary health care

\section{Background}

The increased incidence of impaired glucose metabolism (IGM) $[1,2]$ and its association with vascular complications [3] are serious public health issues. Usually, type 2 diabetes is preceded by a period of hyperinsulinemia as a consequence of insulin resistance (IR), impaired glucose tolerance (IGT) and/or impaired fasting glucose (IFG) [4]. Individuals with IFG have predominantly an increased hepatic insulin resistance and differ from those

\footnotetext{
*Correspondence: ulf.lindblad@allmed.gu.se

${ }^{5}$ Institute of Medicine, Department of Primary Health Care, The Sahlgrenska

Academy of the University of Gothenburg, Gothenburg, Sweden

${ }^{6}$ The Department of primary health care, University of Gothenburg, Box 154, Gothenburg 405 30, Sweden

Full list of author information is available at the end of the article
}

with IGT who primarily have insulin resistance in skeletal muscle [5]. Estimates predict that $60 \%$ of people who develop diabetes have IGT or IFG about 5 years earlier [6]. Sleeping disorders have adverse consequences on multiple systems [7] and several studies link sleeping disorders with IGM and increased risk of developing type 2 diabetes, IGT and IR [8-10]. The causal effects of sleep disorders and the underlying path physiological mechanisms involved have not been fully elucidated [11] and the association between diabetes, obesity and sleep disorders may be described as a vicious circle [12]. Though several behavioral factors may influence these mechanisms, low physical activity and obesity are the

\section{Biomed Central}

(c) 2013 Andersson et al.; licensee BioMed Central Ltd. This is an Open Access article distributed under the terms of the Creative Commons Attribution License (http://creativecommons.org/licenses/by/2.0), which permits unrestricted use, distribution, and reproduction in any medium, provided the original work is properly cited. 
main confounding factors being associated with both IGM, sleep function and experienced well-being.

However, the question remains if the experience of not getting enough sleep to feel thoroughly rested is causally related to the underlying pathophysiological mechanisms in the development of IGT. The feeling of not being fully rested may also be connected to the feeling of low vitality, and fatigue may be one way to express this [13]. Interestingly, we have previously found that people with IGT similarly describe fatigue as abnormal day time sleepiness that increases the need for rest and a feeling of not being as strong as before [13]. An International Diabetes Federation expert committee also recommends professionals consider that patients with IGM may also suffer from sleeping disorders, low vitality and fatigue, and vice versa [14]. Considering that both the American Diabetes Prevention Program [15], and the Finnish Diabetes Prevention Study on IGT [16], using diet and physical activity showed dramatic effects in the prevention of overt diabetes, while similar evidence are lacking for IFG, the focus for preventive strategies is on IGT.

Our aim was accordingly to further characterise subjects with early disturbances in the glucose metabolism being at risk for development of type 2 diabetes. To avoid bias due to secondary effects we identified individuals not yet aware of their condition to explore the association of self-reported lack of sleep and low vitality in relation to IGT in a representative Swedish population.

\section{Methods}

\section{Study population}

The present study is a cross-sectional survey carried out in 2002-2005 in two municipalities in South-western Sweden. Skaraborg County is located in the southwest of Sweden and in the year 2000 had approximately 270,000 inhabitants. The vast majority have lived in Sweden for generations and only a few per cent are immigrants from countries outside Scandinavia. Within the Skaraborg Project a survey was conducted in 2002-2005 in the municipalities of Vara and Skövde, as previously described in detail $(n=2816$, with a participation rate of 76\%) [17]. The participants aged 30-75 were randomly selected from the population in strata by sex and age. Selected participants were invited by mail to participate in a health survey with two visits. The further selection of the current study population of participants with normal glucose tolerance (NGT) or IGT is shown in Figure 1 $(n=2,314$, and $n=213$, respectively). Two subjects had incomplete OGTT, 19 participants did not answer the question on sleep, and 50 subjects did not respond to the question on vitality. The current study populations thus included 2508 participants (lack of sleep) and 2477 (vitality), respectively (Figure 1).

\section{Study procedures}

On the first study visit, specially educated laboratory assistants obtained blood samples in the morning after an overnight fast $(10 \mathrm{~h})$. Plasma glucose was analysed at the

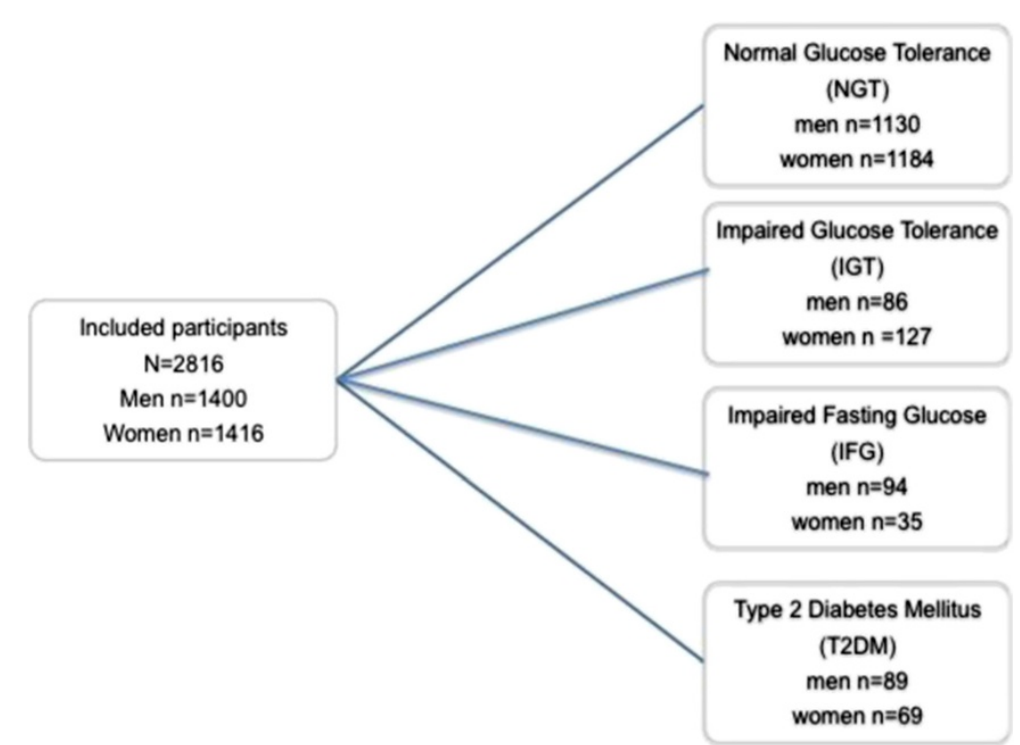

Figure 1 Flowchart of the Skaraborg Project 2002-2005. The total number of participants 2,816, and the participation rate was 76\%. Two participants had incomplete OGTT, and of those with NGT or IGT 19 participants did not answer the question on lack of sleep, and 50 subjects did not respond to the question on vitality. The current study populations thus included 2508 participants (lack of sleep) and 2477 (vitality), respectively. 
hospital laboratory at Kärnsjukhuset, Skövde, Sweden. During the OGTT, the participants were asked to answer a questionnaire covering information about medical history, current medications, socio-economic factors, smoking habits, leisure time physical activity (LTPA), self-rated health and sleeping disorders. The question regarding sleeping disorders used for this paper was: Do you think that you get enough sleep to feel thoroughly rested? The participants chose one of three alternative answers: 1 . Yes, usually. 2. Yes, but not often enough. 3 . No, never or almost never. The question regarding symptoms of vitality was: Have you during the last four weeks felt full of vitality? The six reply alternatives were: 1. Yes, all of the time 2. Yes, most of the time. 3. Yes, a lot of the time. 4. Some of the time. 5. No, almost never. 6. No, not at all. The question was categorized, all/most of the time, a lot of/some of the time and almost never/ not at all, in 3 categories. The question regarding LTPA had four answer alternatives and low physical activity levels 1 and 2, while levels 3-4 were considered physically active [17]. Information on alcohol consumption was collected by a validated questionnaire measuring the total intake of alcohol by beer, wine, and spirits over a 30-days period [18]. A standard resting blood pressure and the anthropometric measures were measured on a second visit two weeks later by two specially trained nurses. Current smoking was defined as daily smoking (yes/no). Concentrations of serum cholesterol were determined using standard procedures. All participants were tested for fasting plasma glucose (FPG), and an OGTT was performed in all patients without a known diagnosis of diabetes. Diagnoses of IFG, IGT and diabetes were determined according to recommendations by WHO [19].

\section{Statistical analyses}

Characteristics of participants with IGT were presented using participants with normal glucose metabolism as a reference, using SPSS Base System 19.0 for Windows for data analyses. Continuous variables were presented as age-adjusted means with SD (standard deviation). Differences in means between groups were analysed by GLM (Generalized linear model) and associations between categories were analysed using logistic regression and expressed as odds ratios (OR) with 95\% CI. All comparisons between groups were adjusted for differences in age and other covariates were included when indicated. All tests were 2-sided and statistical significance was assumed at $\mathrm{p}<0.05$.

\section{Ethical approval}

The study was approved by the Regional ethical review board, Gothenburg University, Sweden (2001-10-15,
Dnr. Ö 199-01) and written consent was obtained from each participant.

\section{Results}

IGT was diagnosed in 213 participants: 86 men and 127 women (Figure 1). Table 1 shows that both men and women with IGT were older than men and women with NGT (Table 1), and they both also had a more atherogenic risk factor profile than participants with NGT. Low level of physical activity, a low level of education, and a diagnosis of hypertension were also more common in both men and women with IGT.

The associations between self-reported lack of sleep and IGT in men and women are shown in Table 2. The OR for IGT in men with a lack of sleep was 2.5 (1.1-5.9), when adjusted for age, BMI, smoking, low level of education, low physical activity and alcohol consumption. No corresponding association was seen in women.

Table 3 shows that when low and severely impaired vitality were compared to normal, significant age-adjusted associations were found between the lowest level of vitality and IGT in both men 2.8 (1.3-5.8), and women 2.0 (1.2-3.4). This association remained in men when further adjusting for BMI, smoking, or level of education but was lost when level of LTPA was entered into the model. In women, the corresponding association remained significant, but was just lost when also alcohol consumption was entered to the model.

We found no associations between lack of sleep and low vitality with IFG (Tables 2 and 3).

\section{Discussion}

We found a significant association between self-reported lack of sleep and IGT in men that remained after adjustment for potential confounders such as obesity and health behaviours. No such association was found in women. Furthermore, a significant association was found between low vitality and IGT in both men and women. While the association was more robust in women, it was lost in men when other patient-related factors were considered. The study also confirmed that both men and women with IGT have a more serious cardiovascular disease risk factor profile than participants with NGT. A worse risk factor profile was also revealed in both men and women with IFG as compared to NGT, however, we found no associations with lack of sleep or low vitality.

In support of our findings, the Quebec Family Study [20] found that both short and long total sleeping time predicted type 2 diabetes/IGT in adult men and women. Clinical effects of sleep deprivation are associated with common symptoms such as sleepiness, increased fatigue, and low motivation [21], a finding that is in agreement with the results of this study. Furthermore, voluntary sleep reduction is increasingly becoming a way of life - 
Table 1 Characteristics of 1.400 men and 1.416 women with normal glucose tolerance (NGT), impaired fasting glucose (IFG) and impaired glucose tolerance (IGT) in the Vara-Skövde cohort 2002-2005

\begin{tabular}{|c|c|c|c|c|c|c|c|c|}
\hline \multirow[b]{3}{*}{ Characteristics } & \multicolumn{2}{|c|}{ NGT } & \multicolumn{3}{|c|}{ IFG } & \multicolumn{3}{|c|}{ IGT } \\
\hline & \multicolumn{2}{|c|}{$(n=1130)$} & \multicolumn{3}{|c|}{$(n=94)$} & \multicolumn{3}{|c|}{$(n=86)$} \\
\hline & Mean & $\overline{(S D)}$ & Mean & (SD) & $p$ & Mean & (SD) & $p$ \\
\hline \multicolumn{9}{|l|}{ Men } \\
\hline Age (years) & 45.9 & $(10.7)$ & 53.4 & $(11.6)$ & $<0.001$ & 56.0 & $(12.3)$ & $<0.001$ \\
\hline $\mathrm{SBP}(\mathrm{mm} \mathrm{Hg})$ & 122 & $(14.3)$ & 129 & $(17.2)$ & 0.093 & 133 & (19.4) & 0.001 \\
\hline $\mathrm{DBP}(\mathrm{mm} \mathrm{Hg})$ & 71 & $(9.7)$ & 74 & $(10.3)$ & 0.157 & 76 & (11.6) & 0.021 \\
\hline S-Cholesterol & 5.4 & $(1.0)$ & 5.2 & $(1.0)$ & 0.009 & 5.6 & $(1.1)$ & 0.559 \\
\hline S-triglycerides & 1.4 & $(0.8)$ & 1.6 & $(0.9)$ & 0.003 & 2.0 & (1.6) & $<0.001$ \\
\hline S-HDL Cholesterol & 1.22 & $(0.28)$ & 1.14 & $(0.35)$ & 0.006 & 1.1 & $(0.3)$ & 0.004 \\
\hline Body mass index $\left(\mathrm{kg} \mathrm{m}^{-2}\right)$ & 26.5 & (3.3) & 28.1 & (3.9) & $<0.001$ & 28.3 & $(4.1)$ & $<0.001$ \\
\hline Waist hip ratio $\left(\mathrm{m} \mathrm{m}^{-1}\right)$ & 0.93 & $(0.1)$ & 0.96 & $(0.1)$ & $<0.001$ & 0.98 & $(0.1)$ & $<0.001$ \\
\hline \multirow[t]{3}{*}{ Waist (cm) } & 94 & $(9.2)$ & 99 & $(10.3)$ & $<0.001$ & 100 & $(11.1)$ & $<0.001$ \\
\hline & \multicolumn{2}{|c|}{ NGT } & \multicolumn{3}{|c|}{ IFG } & \multicolumn{3}{|c|}{ IGT } \\
\hline & \multicolumn{2}{|c|}{$(n=1130)$} & \multicolumn{3}{|c|}{$(n=94)$} & \multicolumn{3}{|c|}{$(n=86)$} \\
\hline Characteristics & $\mathrm{n}$ & (\%) & $\mathrm{n}$ & (\%) & $\mathrm{p}$ & $\mathrm{n}$ & (\%) & $p$ \\
\hline \multicolumn{9}{|l|}{ Men } \\
\hline Lack of sleep & 418 & (37) & 27 & (29) & 0.775 & 33 & (39) & 0.025 \\
\hline Low vitality & 457 & (41) & 38 & $(40)$ & 0.903 & 41 & (50) & 0.056 \\
\hline Daily smoking & 168 & (15) & 18 & (19) & 0.279 & 11 & (13) & 0.638 \\
\hline Low physical activity & 635 & (58) & 60 & (65) & 0.303 & 62 & (77) & 0.002 \\
\hline Hypertension & 111 & (9) & 24 & (26) & 0.063 & 29 & (34) & 0.005 \\
\hline Living alone & 222 & (20) & 16 & (17) & 0.801 & 30 & (35) & $<0.001$ \\
\hline \multirow[t]{3}{*}{ Low level of education } & 307 & $(28)$ & 40 & (44) & 0.570 & 39 & (49) & 0.963 \\
\hline & \multicolumn{2}{|c|}{ NGT } & \multicolumn{3}{|c|}{ IFG } & \multicolumn{3}{|c|}{ IGT } \\
\hline & \multicolumn{2}{|c|}{$(n=1184)$} & \multicolumn{3}{|c|}{$(n=35)$} & & $(n=127$ & \\
\hline Characteristics & Mean & $(\mathrm{SD})$ & Mean & (SD) & $\mathrm{p}$ & Mean & (SD) & $\mathrm{p}$ \\
\hline Women & & & & & & & & \\
\hline Age (years) & 46.2 & $(10.9)$ & 56.3 & $(11.1)$ & $<0.001$ & 53.7 & $(12.8)$ & $<0.001$ \\
\hline $\mathrm{SBP}(\mathrm{mm} \mathrm{Hg})$ & 117 & $(1.0)$ & 131 & $(17.7)$ & 0.022 & 133 & (22.6) & $<0.001$ \\
\hline $\mathrm{DBP}(\mathrm{mm} \mathrm{Hg})$ & 68 & $(9.7)$ & 72 & $(10.1)$ & 0.435 & 74 & $(10.9)$ & $<0.001$ \\
\hline S-Cholesterol & 5.1 & $(1.1)$ & 5.9 & $(1.0)$ & 0.066 & 5.5 & $(0.9)$ & 0.800 \\
\hline S-triglycerides & 1.1 & $(0.54)$ & 1.7 & $(0.7)$ & $<0.001$ & 1.5 & $(0.7)$ & $<0.001$ \\
\hline S-HDL Cholesterol & 1.4 & $(0.33)$ & 1.3 & $(0.36)$ & 0.001 & 1.3 & $(0.4)$ & $<0.001$ \\
\hline Body mass index $\left(\mathrm{kg} \mathrm{m}^{-2}\right)$ & 26.1 & $(4.8)$ & 30.1 & $(6.3)$ & $<0.001$ & 29.6 & $(6.2)$ & $<0.001$ \\
\hline Waist hip ratio $\left(\mathrm{m} \mathrm{m}^{-1}\right)$ & 0.82 & $(0.1)$ & 0.87 & $(0.1)$ & 0.001 & 0.86 & $(0.1)$ & $<0.001$ \\
\hline Waist (cm) & 84 & $(12.5)$ & 94 & $(14.4)$ & $<0.001$ & 92 & $(14.5)$ & $<0.001$ \\
\hline & & & & IFG & & & IGT & \\
\hline & & & & $(n=35)$ & & & $(n=127$ & \\
\hline Characteristics & $\mathrm{n}$ & $(\%)$ & $\mathrm{n}$ & $(\%)$ & $p$ & $\mathrm{n}$ & (\%) & $\mathrm{p}$ \\
\hline Women & & & & & & & & \\
\hline Lack of sleep & 466 & $(40)$ & 16 & (47) & 0.195 & 52 & (41) & 0.413 \\
\hline Low vitality & 698 & (52) & 21 & $(60)$ & 0.301 & 74 & (61) & 0.048 \\
\hline Daily smoking & 246 & $(21)$ & 9 & (26) & 0.272 & 23 & (18) & 0.706 \\
\hline Low physical activity & 791 & (69) & 26 & (79) & 0.336 & 107 & (86) & $<0.001$ \\
\hline
\end{tabular}


Table 1 Characteristics of 1.400 men and 1.416 women with normal glucose tolerance (NGT), impaired fasting glucose (IFG) and impaired glucose tolerance (IGT) in the Vara-Skövde cohort 2002-2005 (Continued)

\begin{tabular}{lllllllll}
\hline Hypertension & 111 & $(10)$ & 7 & $(20)$ & 0.872 & 46 & $(36)$ & $<0.001$ \\
Living alone & 225 & $(19)$ & 6 & $(17)$ & 0.381 & 26 & $(21)$ & 0.679 \\
Low level of education & 236 & $(20)$ & 18 & $(512)$ & 0.228 & 44 & $(36)$ & 0.759 \\
\hline
\end{tabular}

NGT normal glucose tolerance, IFG impaired fasting glucose, IGT impaired glucose tolerance. SBP systolic blood pressure, DBP diastolic blood pressure.

Data are means and (SD), or numbers and proportions (\%). IFG and IGT were compared to NGT using general linear models for continues variables, and logistic regression for categorical variables and adjusting for differences in age.

a habit related to the modern 24 hour society [22], and studies show that nearly $30 \%$ of the middle-aged population reported sleeping less than $6.5 \mathrm{~h}$ per night [23]. As a consequence, reports of day-time sleepiness have become more frequent during recent years [24]. The cause of sleep-loss is multi factorial, although obesity is considered an important risk factor for obstructive sleep apnea (OSA) [25]. Accordingly, in the FIN-D2D survey [26], middle-aged men with sleep-disorderedbreathing (SDB) had an increased incidence of type 2 diabetes and abnormal glucose tolerance. However, no corresponding association has been found in women in either the FIN-D2D survey [26] or the study of women in Gothenburg [27].

The significant association found between level of vitality and IGT was robust in women, but was diluted and lost in men when successively accounting for other patient-related factors. As fatigue is one of the more common presenting symptoms of type 2 diabetes, this is interesting. Physical activity came out as an explanatory factor in men, but an interaction should be expected in both genders by virtue of its strong association with insulin resistance and consequently the development of both IGT and type 2 diabetes [28]. Since physical activity is known to improve mood, and a good mood most likely increase the motivation for physical activity it may thus also be associated with the vitality factor [29].

As shown in a prospective study, psychological distress such as fatigue, anxiety and insomnia increases the risk for prediabetes and type 2 diabetes in Swedish middleaged men [30]. There is a common belief that day-time sleepiness is normal or related to poor life style or laziness, especially if it interferes with daily functions [28]. However, OSA often characterized by daytime

Table 2 Association between lack of sleep and impaired glucose tolerance and impaired fasting glucose, respectively, using normal glucose tolerance as reference

\begin{tabular}{|c|c|c|c|c|c|c|c|c|c|}
\hline \multirow{2}{*}{$\begin{array}{c}\text { None } \\
\text { OR }\end{array}$} & \multicolumn{2}{|c|}{ Intermediate } & \multicolumn{2}{|c|}{ Severe } & \multirow{2}{*}{$\begin{array}{c}\text { None } \\
\text { OR }\end{array}$} & \multicolumn{2}{|c|}{ Intermediate } & \multicolumn{2}{|c|}{ Severe } \\
\hline & OR & $95 \% \mathrm{Cl}$ & OR & $95 \% \mathrm{Cl}$ & & OR & $95 \% \mathrm{Cl}$ & OR & $95 \% \mathrm{Cl}$ \\
\hline
\end{tabular}

Lack of sleep and the association with IGT

Adjusted for age

1

1.6

$(0.9-2.7)$

2.4

(0.9-2.6)

2.3

2.4

$(1.1-5.3)$

2.6

(1.2-5.9)

(0.8-2.5)

Adjusted for age, BMI, smoking, level of education, level of physical activity

(0.7-2.3)

2.3

$(1.0-5.5)^{*}$

1

Adjusted for age, BMI, smoking, level of education, level of physical activity, alcohol consumption
1.3
(0.7-2.3)

2.5

(1.1-5.9)

(0.7-1.7)

$(0.8-1.8)$

1.1

(0.5-2.2)

Lack of sleep and the association with IFG

Adjusted for age

$$
1.0
$$

$$
\text { (0.6-1.7) }
$$

0.7

$(0.2-1.9)$

1

1.5

$(0.7-3.2)$

1.9

$(0.6-5.9)$ 
Table 3 Association between low vitality and impaired glucose tolerance and impaired fasting glucose, respectively, using normal glucose tolerance as reference

\begin{tabular}{|c|c|c|c|c|c|c|c|c|c|}
\hline \multirow{2}{*}{$\begin{array}{c}\text { None } \\
\text { OR }\end{array}$} & \multicolumn{2}{|c|}{ Intermediate } & \multicolumn{2}{|c|}{ Severe } & \multirow{2}{*}{$\begin{array}{c}\text { None } \\
\text { OR }\end{array}$} & \multicolumn{2}{|c|}{ Intermediate } & \multicolumn{2}{|c|}{ Severe } \\
\hline & OR & $95 \% \mathrm{Cl}$ & OR & $95 \% \mathrm{Cl}$ & & OR & $95 \% \mathrm{Cl}$ & OR & $95 \% \mathrm{Cl}$ \\
\hline
\end{tabular}

Low vitality and the association with IGT

Adjusted for age

1

Adjusted for age, BMI

1

Adjusted for age, BMI, smoking

$$
1 \quad 1.4
$$

2.7

$(1.3-5.7)$

1

Adjusted for age, BMI, smoking, level of education

$$
\begin{array}{llll}
1 & 1.3 & (0.8-2.3) & 2.2
\end{array}
$$

1

Adjusted for age, BMI, smoking, level of education, level of physical activity

$$
\begin{array}{lllll}
1 & 1.1 & (0.6-1.9) & 2.0 & (0.9-4.4)
\end{array}
$$

(0.9-4.4) $\quad 1$

Adjusted for age, BMI, smoking, level of education, level of physical activity, alcohol consumption
1
$1.1 \quad$ (0.6-2.0)
2.0
(0.9-4.6)
1
1.3
$(0.8-2.1)$
1.7
(0.9-3.0)

Low vitality and the association with IFG

Adjusted for age

IGT impaired glucose tolerance, IFG impaired fasting glucose, $B M I$ body mass index. Associations were estimated using logistic regression and were expressed by OR and $95 \%$ confidence intervals. ${ }^{*} \mathrm{p}=0.048$.

sleepiness, and diabetes share common mechanisms including age and obesity, but the direction of causality may go both ways [28]. Consequently, OSA should also be considered when these symptoms are investigated. The underlying mechanism also involving genetics, for example a mutation in the melatonin receptor $1 \mathrm{~B}$, should also be considered [31].

Our study question on sleep function did not account for sleep duration or possible SDB. However, the difference between men and women in the association between lack of sleep and IGT is consistent with the findings in the FIN-D2D study [26], and might thus be explained by the fact that men are more exposed to OSA, or more susceptible to the effects of OSA. Nevertheless, our findings were not diluted when BMI was adjusted for. Unfortunately, we did not measure breathing pattern during sleep directly or by questionnaire. In a previous Swedish study, men were also more susceptible to psychological distress in the association with prediabetes than women [30]. We found no corresponding pattern in the association with low vitality. This may probably be explained by low vitality being derived from other mechanisms than psychological distress.

\section{Strengths and limitations of the study}

This study is based on a large, random population sample with a high participation rate, making the results generalizable to this and other similar populations. A further strength of this study is the enrolment of both men and women over a wide age-band where strategies of diabetes prevention are important. The prevalence of IGT was also congruent with other studies from Sweden [30].

An OGTT was performed in each participant without a known diagnosis of diabetes. According to recommendations from WHO, an OGTT should be performed to diagnose IGT as it is characterized by postprandial hyperglycemia and separate from IFG that is characterized by fasting hyperglycemia. This procedure to identify IGT is supported by experiences from other population studies [32]. The questionnaires were completed before the information of the results of the OGTT was available, and therefore none of the participants were aware of their potential diagnosis of IGT when answering the questionnaire. In this study we used self-reported information on physical activity on physical activity in leisure time, (LTPA). However, this question has shown good validity when recently compared to objectively measured total physical activity during 24 hour [33]. Limitations of the study comes from it's cross-sectional design, making it impossible to decide on causality in associations. Information on sleep function and vitality was selfreported and not based on direct measurements; however, these questions have been used and validated in 
other studies with reliable findings. Thus, non-restorative sleep was explored in the Minimal Insomnia Symptom Scale (MISS) [34], and our question on vitality was included in a validation of the SF-36 questionnaire [35]. The question on self-experienced lack of sleep in this study is a general perception on the sleep quality covering both sleep duration and sleep quality as compared to instruments that evaluate more specific domains of sleep quality like the Pittsburg Slep Quality Index [36]. It still correlates well with other characteristics of sleep function [34]. Finally, the protocol did not comprise any measurements on OSA and HbAlc was not measured in the complete sample, and thus these important factors could not be accounted for.

\section{Conclusions}

There is a link between self-reported lack of sleep, low vitality and IGT. Short sleep duration is a risk factor for developing type 2 diabetes [37] and voluntary sleep restriction may contribute to the global epidemic burden of type 2 diabetes [10]. More research is needed to determine how quality of sleep and low vitality interact in persons who are susceptible to developing IGT, thus facilitating improved strategies for prevention.

For health professionals, this study emphasizes the importance of paying attention to patients' symptoms of sleep deficiency and low vitality. Patients with lack of sleep and low vitality should be considered for evaluation of a possible IGT in line with the IDF expert committee [14]. In particular, male patients with insufficient sleep and related symptoms such as low vitality should be tested generously for possible impaired glucose metabolism, using OGTT more frequently. This is correspondingly true for women expressing low vitality. Our findings are in accordance with the current strategy of opportunistic screening and primary care is the legitimate setting for primary prevention of type 2 diabetes. Listening to the patients' symptoms may be one way of helping to identify persons at risk in order to prevent the development of type 2 diabetes.

\section{Competing interests}

The authors declare that they have no competing interests.

\section{Authors' contributions}

All authors conceived of the study, and UL supervised the data collection. SA, EB-H and UL participated in the data and statistical analysis. SA has collect data, been involved in drafting the study, interpretation of data and manuscript review. UL has drafted and coordinated the study design, led the analysis of the cross sectional data and full manuscript development. IE has been involved in drafting the study, interpretation of data, manuscript review, editing for intellectual content. FF has been involved in drafting the study interpretation of data, manuscript review and editing for intellectual content. EB-H has collect data, been involved in drafting the study and the interpretation of data, manuscript review and editing for intellectual content. All authors read and approved the final manuscript.

\section{Acknowledgements}

The study was funded by the National Research Foundation Council (VR), Sweden The Skaraborg Institute in Skövde, Sweden, Skaraborg Primary Care, Sweden, The
Health \& Medical Care Committee of the Regional Executive Board of the Region Västra Götaland, Sweden, University of Skövde, Sweden and The Sahlgrenska Academy at the University of Gothenburg, Sweden. The authors would also like to thank the participants from Vara and Skövde who made this study possible.

\section{Author details}

${ }^{1}$ Institute of Health and Care Sciences, The Sahlgrenska Academy of the University of Gothenburg, Gothenburg, Sweden. ${ }^{2}$ School of Life Sciences, University of Skövde, P.O. Box 408, 54128 Skövde, Sweden. ${ }^{3}$ Centre for Person-Centred Care (GPCC), University of Gothenburg, P.O. Box 457140530 Gothenburg, Sweden. ${ }^{4}$ Faculty of Social Sciences, Department of Health, University of Stavanger, Stavanger, Norway. ${ }^{5}$ Institute of Medicine, Department of Primary Health Care, The Sahlgrenska Academy of the University of Gothenburg, Gothenburg, Sweden. ${ }^{6}$ The Department of primary health care, University of Gothenburg, Box 154, Gothenburg 405 30, Sweden.

Received: 3 January 2013 Accepted: 22 July 2013

Published: 31 July 2013

\section{References}

1. Shaw JE, Sicree RA, Zimmet PZ: Global estimates of the prevalence of diabetes for 2010 and 2030. Diabetes Res Clin Pract 2009, 87:4-14.

2. Rao SS, Disraeli P, McGregor T: Impaired glucose tolerance and impaired fasting glucose. Am Fam Physician 1961, 2004:69.

3. Barzilay Jl, Spiekerman CF, Wahl PW, Kuller LH, Cushman M, Furberg CD, Dobs A, Polak JF, Savage PJ: Cardiovascular disease in older adults with glucose disorders: comparison of American Diabetes Association criteria for diabetes mellitus with WHO criteria. Lancet 1999, 354:622-625.

4. Martin BC, Warram JH, Krolewski AS, Bergman RN, Soeldner JS, Kahn CR: Role of glucose and insulin resistance in development of type 2 diabetes mellitus: results of a 25-year follow-up study. Lancet 1992, 340:925-929.

5. Abdul-Ghani MA, Defronzo RA: Pathophysiology of prediabetes. Curr Diab Rep 2009, 9:193-199.

6. Unwin N, Shaw J, Zimmet P, Alberti KG: Impaired glucose tolerance and impaired fasting glycaemia: the current status on definition and intervention. Diabet Med 2002, 19:708-723.

7. Pack Al, Pien GW: Update on sleep and its disorders. Annu Rev Med 2011, 62:447-460.

8. Seicean S, Kirchner HL, Gottlieb DJ, Punjabi NM, Resnick H, Sanders M, Budhiraja R, Singer M, Redline S: Sleep-disordered breathing and impaired glucose metabolism in normal-weight and overweight/obese individuals: the Sleep Heart Health Study. Diabetes Care 2008, 31:1001-1006.

9. Punjabi NM, Sorkin JD, Katzel LI, Goldberg AP, Schwartz AR, Smith PL: Sleepdisordered breathing and insulin resistance in middle-aged and overweight men. Am J Respir Crit Care Med 2002, 165:677-682.

10. Gottlieb DJ, Punjabi NM, Newman AB, Resnick HE, Redline S, Baldwin CM, Nieto FJ: Association of sleep time with diabetes mellitus and impaired glucose tolerance. Arch Intern Med 2005, 165:863-868.

11. Punjabi NM: Do sleep disorders and associated treatments impact glucose metabolism? Drugs 2009, 69(Suppl 2):13-27.

12. Barone MT, Menna-Barreto L: Diabetes and sleep: a complex cause-andeffect relationship. Diabetes Res Clin Pract 2010, 91:129-137.

13. Andersson S, Ekman I, Lindblad U, Friberg F: Perceived Symptoms in People Living with Impaired Glucose Tolerance. Nurs Res Pract 2011. doi:10.1155/2011/937038.

14. Shaw JE, Punjabi NM, Wilding JP, Alberti KG, Zimmet PZ: Sleep-disordered breathing and type 2 diabetes: a report from the International Diabetes Federation Taskforce on Epidemiology and Prevention. Diabetes Res Clin Pract 2008, 81:2-12.

15. Knowler WC, Barrett-Connor E, Fowler SE, Hamman RF, Lachin JM, Walker EA, Nathan DM: Diabetes Prevention Program Research Group. Reduction in the incidence of type 2 diabetes with lifestyle intervention or metformin. N Engl J Med 2002, 7:393-403.

16. Tuomilehto J, Lindström J, Eriksson JG, Valle TT, Hämäläinen $\mathrm{H}$, llanne-Parikka $\mathrm{P}$, Keinänen-Kiukaanniemi S, Laakso M, Louheranta A, Rastas M, Salminen V, Uusitupa M: Finnish Diabetes Prevention Study Group. Prevention of type 2 diabetes mellitus by changes in lifestyle among subjects with impaired glucose tolerance. N Engl J Med 2001, 3:1343-1350.

17. Larsson CA, Gullberg B, Råstam L, Lindblad U: Salivary cortisol differs with age and sex and shows inverse associations with WHR in Swedish women: a cross-sectional study. BMC Endocrin Disord 2009, 9:16. 
18. Göransson M, Hanson BS: How much can data on days with heavy drinking decrease the underestimation of true alcohol consumption? J Stud Alcohol 1994, 55:695-700.

19. Alberti KG, Zimmet PZ: Definition, diagnosis and classification of diabetes mellitus and its complications. Part 1: diagnosis and classification of diabetes mellitus provisional report of a WHO consultation. Diabet Med 1998, 15:539-553.

20. Chaput JP, Despres JP, Bouchard C, Astrup A, Tremblay A: Sleep duration as a risk factor for the development of type 2 diabetes or impaired glucose tolerance: analyses of the Quebec Family Study. Sleep Med 2009, 10:919-924

21. Bonnet MH, Arand DL: Clinical effects of sleep fragmentation versus sleep deprivation. Sleep Med Rev 2003, 7:297-310.

22. Schubert CR, Cruickshanks KJ, Dalton DS, Klein BE, Klein R, Nondahl DM: Prevalence of sleep problems and quality of life in an older population. Sleep 2002, 25:889-893.

23. Bonnet MH, Arand DL: We are chronically sleep deprived. Sleep 1995 , 18:908-911.

24. Pagel JF: Excessive daytime sleepiness. Am Fam Physician 2009, 79:391-396.

25. Young T, Peppard PE, Taheri S: Excess weight and sleep-disordered breathing. J Appl Physiol 2005, 99:1592-1599.

26. Tuomilehto H, Peltonen M, Partinen M, Seppa J, Saaristo T, Korpi-Hyovalti E, Oksa H, Saltevo J, Puolijoki H, Vanhala M, Tuomilehto J: Sleep-disordered breathing is related to an increased risk for type 2 diabetes in middleaged men, but not in women-the FIN-D2D survey. Diabetes Obes Metab 2008, 10:468-475.

27. Björkelund C, Bondyr-Carlsson D, Lapidus L, Lissner L, Månsson J, Skoog I, Bengtsson C: Sleep disturbances in midlife unrelated to 32-year diabetes incidence: the prospective population study of women in Gothenburg. Diabetes Care 2005, 28:2739-2744.

28. Tuomilehto J: Nonpharmacologic therapy and exercise in the prevention of type 2 diabetes. Diabetes Care 2009, 32:S189-193.

29. Hegadoren KM, O'Donnell T, Lanius R, Coupland NJ, Lacaze-Masmonteil N: The role of beta-endorphin in the pathophysiology of major depression. Neuropeptides 2009, 43:341-353.

30. Eriksson AK, Ekbom A, Granath F, Hilding A, Efendic S, Östenson CG: Psychological distress and risk of pre-diabetes and Type 2 diabetes in a prospective study of Swedish middle-aged men and women. Diabet Med 2008, 25:834-842.

31. Prokopenko I, Langenberg C, Florez JC, Saxena R, Soranzo N, Thorleifsson G, Loos RJ, Manning AK, Jackson AU, Aulchenko Y, Potter SC, Erdos MR, Sanna S, Hottenga JJ, Wheeler E, Kaakinen M, Lyssenko V, Chen WM, Ahmadi K, Beckmann JS, Bergman RN, Bochud M, Bonnycastle LL, Buchanan TA, Cao A, Cervino A, Coin L, Collins FS, Crisponi L, de Geus EJ, et al: Variants in MTNR1B influence fasting glucose levels. Nat Genet 2009, 41:77-81.

32. Bartnik M, Ryden L, Malmberg K, Öhrvik J, Pyörälä K, Standl E, Ferrari R, Simoons M, Soler-Soler J: Oral glucose tolerance test is needed for appropriate classification of glucose regulation in patients with coronary artery disease: a report from the Euro Heart Survey on Diabetes and the Heart. Heart 2007, 93:72-77.

33. Emaus A, Degerstrøm J, Wilsgaard T, Hansen BH, Dieli-Conwright CM, Furberg AS, Pettersen SA, Andersen LB, Eggen AE, Bernstein L, Thune I: Does a variation in self-reported physical activity reflect variation in objectively measured physical activity, resting heart rate, and physical fitness? Results from the Tromsø study. Scand J Public Health 2010, 38:105-118.

34. Broman JE, Smedje H, Mallon L, Hetta J: The Minimal Insomnia Symptom Scale (MISS): a brief measure of sleeping difficulties. Upsala J Med Sci 2008, 113:131-142

35. Brazier JE, Harper R, Jones NMB, O'Cathain A, Thomas KJ, Usherwood T, Westlake L: Validating the SF-36 health survey questionnaire: new outcome measure for primary care. BMJ 1992, 305:160-164.

36. Buysse DJ, Reynolds CF, Monk TH, Berman SR, Kupfer DJ: The Pittsburgh Sleep Quality Index (PSQI): A new instrument for psychiatric research and practice. Psychiatry Res 1989, 28:193-213.

37. Yaggi HK, Araujo AB, McKinlay JB: Sleep duration as a risk factor for the development of type 2 diabetes. Diabetes Care 2006, 29:657-661.

doi:10.1186/1471-2458-13-700

Cite this article as: Andersson et al: The association between selfreported lack of sleep, low vitality and impaired glucose tolerance: a Swedish cross-sectional study. BMC Public Health 2013 13:700.

\section{Submit your next manuscript to BioMed Central and take full advantage of:}

- Convenient online submission

- Thorough peer review

- No space constraints or color figure charges

- Immediate publication on acceptance

- Inclusion in PubMed, CAS, Scopus and Google Scholar

- Research which is freely available for redistribution 